\title{
Analysis of Public Space in Historic Districts of Historic Cities Based on
}

\section{Community Governance}

\author{
Fan Ding, Yunying Ren* \\ Xian University of Architecture \& Technology, Xian Shaanxi, China \\ *Corresponding Author.
}

\begin{abstract}
Purpose: Based on the perspective of community governance, the paper explores the research path of public space renewal in historic city districts. Taking the historical public space of Lhasa City as an example, this paper analyzes the causes of the characteristics of public space, analyzes the logical relationship between public space and urban renewal and community governance, and finally optimizes the pattern of historical public space of Lhasa City by improving the spatial structure. Create intelligent living blocks and optimize the life mode of historical blocks; Significance: From the human-oriented perspective, the exploration of the public space renewal in the Historic Districts was in essence a process in which people develop continuously and their needs are continuously satisfied. It could meet the multi-level needs of residents at different stages. Secondly, from a social perspective, the innovative pattern of community governance could help achieve self-satisfaction within the district, radiate to the surrounding industries, and relieve the pressure of social employment. Thirdly, from the perspective of urban renewal implementation, the research on the public space renewal the Historic Districts would help promote the balance of social ecological environment, improve the regional governance and promote the high-quality development of the city.
\end{abstract}

Keywords: public space, community governance, the Historic Districts, Lhasa

\section{Introduction}

As China's urbanization has exceeded 60 percent and the urbanization process has entered the middle and later stages, China's economy has shifted from a stage of high-speed growth to a stage of high-quality development. The development and changes of the China's main social contradiction at this stage has brought out new characteristics of China's urbanization, making it clear that we face new tasks including driving force transformation, mode transformation and structural adjustment. In the past, one-sided radical construction methods were often adopted in single projects and individual interests, but they can hardly meet the needs of the new era [1-3]. In 2021, it has been clearly pointed out in the 14 ${ }^{\text {th }}$ Five-Year Plan for National Economic and Social Development of the People's Republic of China and the Outline of the 2035 Vision Goal: "implement urban renewal actions and improve the quality of urbanization development". In the future, the urban construction will enter the era of refined operation from the past extensive development. Therefore, the renewal of the old urban district of Lhasa focuses on individuals' yearning for a better life under the background of stock, which has been the consensus of the times for urban planning and development [4].

\section{Questions in Focus}

The public space in Historic Districts, as the basic urban space unit, is not only a place where residents live their daily life, but also a flexible space to deal with emergencies. People have increasingly realized the diversity and inclusiveness of the basic public space as well as its important value in responding to crises and improving urban

ISSN: 0010-8189

C CONVERTER 2021 
tenacity especially during the national campaign against COVID-19. As the comprehensive value about the renewal planning of public space in the Historic Districts was not fully recognized in the past, certain gaps existed between the implementation level and the planning vision. The practical needs of residents' daily life were often ignored and the simplified renewal work was pushed forward slowly, so the residents were not satisfied with the renewal results. As the public space lacks vitality and self-renewability in the Historic Districts, it is difficult to form a good and sustainable development mode. Therefore, the future renewal of the Historic Districts aims at the following aspects: to correctly understand the organic connections between public space renewal, community governance and urban renewal in the stage of high-quality development in China's Historic Districts of Historic Cities, to respond to current residents' demands, and to actively build a vigorous and healthy public space in the Historic Districts. It is also an inevitable requirement to promote the high-quality development of the city [5-7].

Influenced by natural climate, historical and cultural background, religion and folk customs, the public space in the Historic Districts of Lhasa shows a unique spatial form with distinct regional characteristics and strong ethnic characteristics in historical accumulation. However, it is difficult to balance and coordinate during the public space renewal in the Historic Districts of Lhasa in reality [8]. Because of the contradictions between regionalism, national characters and urban renewal, the public space is declining in the Historic Districts of Lhasa [9].

\section{Analysis of The Causes}

Influenced by the natural environment of the plateau, religions and ethnic culture, the public space in the Historic Districts of Lhasa is complex and diverse with distinct regional characteristics. For this reason, this paper started from the internal causes why the public space was formed in the Historic Districts of Lhasa. It then identified its performance characteristics and established the logical relationship (as shown in Figure 1).

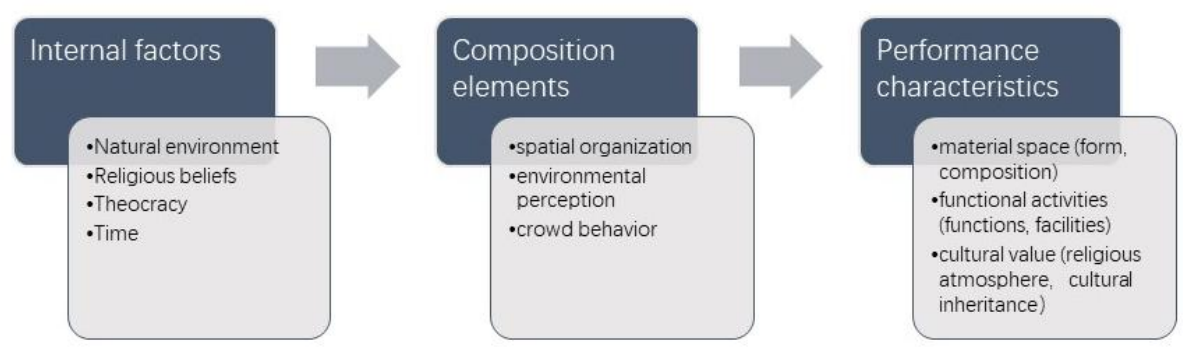

Figure 1 logical relationships between the causes of the characteristics

\subsection{Introduction to the Historic Districts t of Lhasa}

Located in Chengguan District, the Historic Districts of Lhasa is an enclosed district including west of Linkuo East Road, east of Duosenge Road, north of Jiangsu Road, and south of Linkuo North Road (as shown in Figure 2). With Jokhang Temple as the core, Barkhor Block covers an area of about 5.3h square meters and its buffer area is about 128.6h square meters, including four subdistrict offices of Ji Beng Gang, Barkhor Street, Chong Sai Kang and $\mathrm{Ji} \mathrm{Ri}$ and the 15 community neighborhood committees under their jurisdiction [10-12].

The population is mainly made up of local residents and tourists. Local residents are mainly old inhabitants in the region. A small part of them are Muslims and Nepalese who have lived in Lhasa for more than ten generations. In the peak season (from June to September), tourists are mainly from different places at home and abroad, while in the off-season (from September to May), the majority of the tourists are the religious pilgrims [13,14].

ISSN: 0010-8189

(C) CONVERTER 2021 


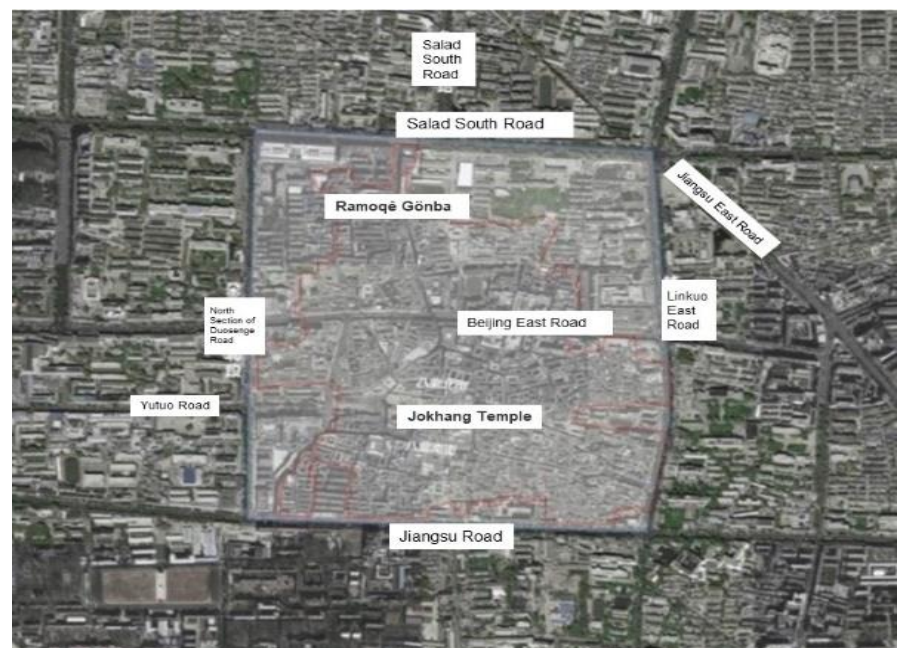

Figure 2 Scope of old Historic Districts of Lhasa (painted by the author)

\subsection{Formation of internal causes}

\subsubsection{Natural environment}

The Historic Districts of Lhasa is located in the valley plain of the lower reaches of Lhasa River---a tributary of Yarlung Zangbo River. The terrain slopes gently and the soil is fertile. Influenced by the Gangdise-Nienqentangula and Himalayas in the east-west direction, the climate is mild and semi-arid. With sufficient sunshine, the annual sunshine time is about $3000 \mathrm{~h}$, so the solar radiation is strong. The temperature varies greatly between day and night. The land with arid climate and few natural disasters provided a suitable space for the formation of the Historic Districts of Lhasa.

\subsubsection{Religious beliefs}

Directly influenced by Buddhism, the public space in the Historic Districts of Lhasa is not only the daily living space of residents, but also the ritual space of Tibetan Buddhism. With Jokhang Temple as the center, there are three layers of roads for turning scripture, namely, Nunkhor, Barkhor and Linkhor. They reveal the cognitive expression that the Indian Buddhism understand the cosmic order through the mandala pattern. Under the influence of Tibetan Buddhism, religious disciples walked around the spinning scripture wheels clockwise to express their sincere faith. It is in such activities that the spatial form and road network structure of the Historic Districts of Lhasa were formed, with Jokhang Temple as the core.

\subsubsection{Theocracy system}

From the introduction of Buddhism in the 7th century to the time when the Gelug school was in power, the politics and religion in Tibet developed into a theocratic system. The religious power reflects the social hierarchy of Tibet through the institutional influence, which is then projected into the urban spatial form and order. With Jokhang Temple as the core, the public space of Lhasa serves as the center of religious activities and directly influences the urban spatial form of Lhasa. The spatial form and spatial construction of the public space are also the reflection of the theocracy system in the Historic Districts of Lhasa.

\subsection{Composition elements}

\subsubsection{Spatial pattern}

The original spatial form of the traditional Tibetan city has been completely preserved in the spatial pattern of the Historic Districts of Lhasa to a certain extent. In the Historic Districts of Lhasa, temples, Lama's residence, dratsang (schools), mansions, residences and trade markets are determined by the hierarchy of buildings, and the spatial density of buildings decreases based on how far they are from religious buildings. Barkhor, a place for reciting Buddhist scriptures, unifies the urban traffic function and religion functions perfectly. It also plays a decisive role in the spatial form and the road network structure of the Historic Districts of Lhasa. With Jokhang temple as the core, buildings and religious activities naturally develop outward into the spatial pattern of the Historic Districts of Lhasa. Meanwhile, the distinct spatial from reflects the strong awareness towards religion, politics and customs.

ISSN: 0010-8189 


\subsubsection{Environmental perception}

Lhasa is located in the plateau. Influenced by the natural and geographical environment, Tibetan residents have achieved the unification of space and environment as well as the wisdom of harmonious coexistence after cumulative experience over a long period of time. Under the influence of Buddhism, the spatial pattern is naturally formed with Jokhang Temple as the core, which has been affecting the development of Lhasa and conveys the unique psychological quality and cultural atmosphere of the Tibetans. A rich religious atmosphere is constituted by temples, prayer flags, incense burners, pagodas, etc., in the Historic Districts of Lhasa. Since residents have the same beliefs, folk customs and living habits there, they have formed an emotional resonance with a sense of belonging. In addition, it also affects tourists' feelings towards national and regional culture.

\subsubsection{Crowd behavior}

The religious activity space formed by religious buildings is a main component of the public space in the Historic Districts of Lhasa. At present, 23 religious buildings are preserved in the old urban district of Lhasa, including the representative Jokhang Temple, Ramoche Temple, Gyümé Temple, Tengyeling Temple, etc. The public space with Jokhang Temple as the center is an important place to hold religious ritual activities. Pilgrims kowtow in Jokhang Temple and disciples recite Buddhist scriptures around Barkhor Street. They recite the six-word mantra and spin prayer wheels of different colours while walking hurriedly. They are totally absorbed in the rituals without distractions and hide their firm beliefs in their hearts.

Along with the demands of the new era, some changes have already taken place in the traditional urban spatial form of the Historic Districts of Lhasa. For example, some streets and lanes are disorganized, and the expansion of the outer boundary weakens the spatial form there. The characteristics of the traditional public space with Jokhang Temple as the center tend to disappear gradually. The factors including the aging of the social structural form, population flow and high commercial density directly affect the community structure stability in the Historic Districts of Lhasa. Since the ethnic culture value is underestimated, the cultural atmosphere also weakens and the cultural inheritance fails in the Historic Districts of Lhasa. In conclusion, based on respecting the regional cultural characteristics, it is the core issue of the public space renewal in the Historic Districts of Lhasa to coordinate the contradictions and meet the residents' needs. Therefore, this paper adopted the perspective of community governance innovation and explored the public space renewal methods in Historic Districts of Lhasa from six aspects: space renewal, structure improvement, life reorganization, diversified construction, and innovative ways and system construction (as shown in Figure 3).

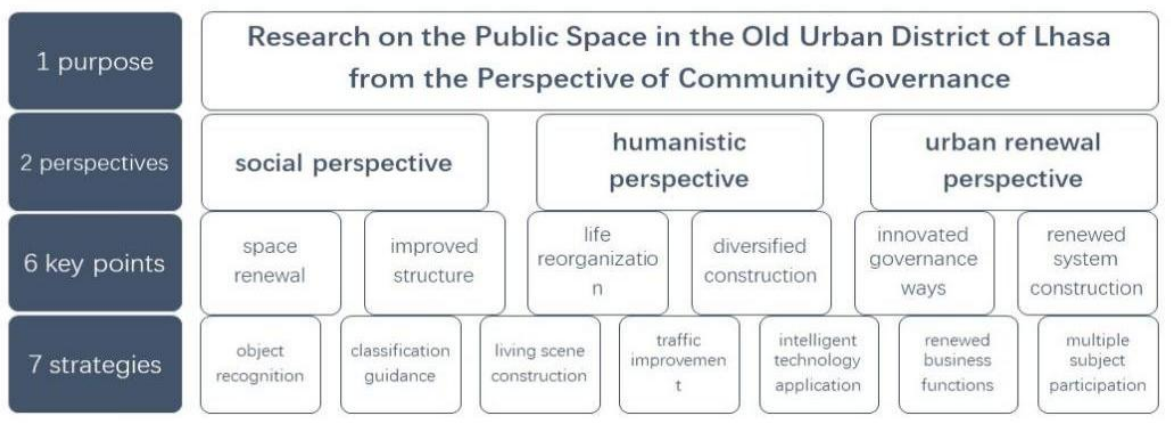

Figure 3 research thoughts of public space renewal in Historic Districts of Lhasa

\section{Relationships between Community Governance Innovations and Public Space Renewal in the Historic Districts of Lhasa in the New Development Stage}

\subsection{Time cognition of community governance}

Community governance is the means to solve the complex contradictions and meet the needs of residents arising from the rapid development of urbanization, and it is also the main way to promote community planning. Community planning not only provides residents with daily life, but also serves as the main battlefield of future urban planning in the new development stage. The shortcomings of basic space units were profoundly realized

ISSN: 0010-8189

(C) CONVERTER 2021 
especially after the epidemic. Therefore, it is important to correctly understand the era characteristics of community governance at the new development stage of China. The community governance has shifted from spatial planning to spatial renewal and from government domination to multi-consultation and co-construction. Moreover, emerging technology is used to satisfy residents' specific needs of living healthy life. These will become the objectives of the future community governance innovation.

4.2 Action mechanism of the public space renewal of the Historic Districts of Lhasa from the perspective of community governance innovations

Communities are the cells of the city, and the organic renewal is a process for the urban metabolism. Space governance is carried out to protect the Historic Districts, while the social governance is achieved mainly through community governance innovations. There is a coupling driven relationship between space governance and social governance. The community development focuses on people, so residents should play a leading role in in community planning and construction to promote the effective protection of the Historic Districts. Meanwhile, the effectiveness of community governance is improved in the organic urban renewal in order to achieve a positive cycle for urban development and renewal as well as the community governance innovations.

This paper first sorted out the space, functions, activities, crowds and regulations of the Historic Districts of Lhasa, and then clarified the logical relationship between community governance and the Historic Districts renewal. The logical relationship is in material form manifested as basically preserving the traditional spatial pattern of the Historic Districts.

The traditional lifestyles of local residents and the space for religious activities should be preserved for local residents. And the culture of the Historic Districts of Lhasa is inherited based on the tourism industry. This paper put forward the public space renewal strategies of the Historic Districts of Lhasa from humanistic perspective, social perspective and urban renewal perspective. (As shown in Figure 4-1, 4-2)
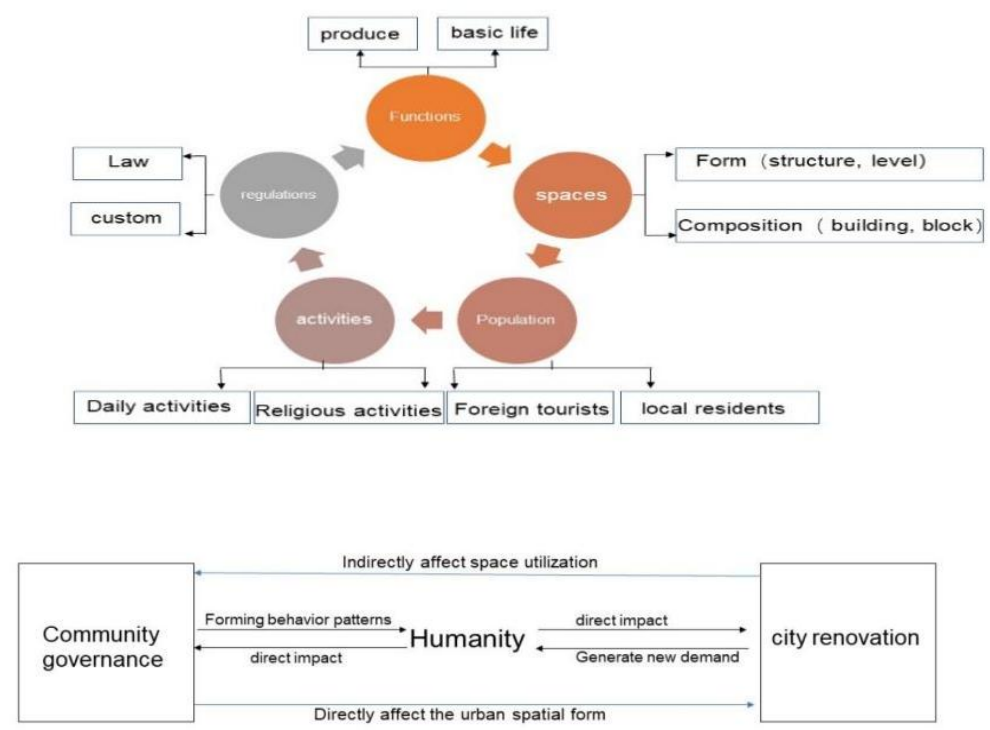

Figure 4-1, 4-2 Action mechanism of the public space renewal of Historic Districts of Lhasa

\section{Public Space Renewal Strategies of Historic Districts of Lhasa from the Perspective of Community}

\section{Governance Innovations}

In the new development stage, the construction of a comprehensive, accurate and dynamic renewal system of public space in the Historic Districts is an important reflection of community development and governance as well as an inevitable requirement to promote high-quality urban development. The author took the public space in the Historic Districts of Lhasa as an example. Based on the spatial distribution level of the old urban district of Lhasa,

ISSN: 0010-8189

(C) CONVERTER 2021 
this paper started from the community governance innovations and focused on the research approach about the space renewal of the Historic Districts of Lhasa from three aspects: "community space renewal", "community life reorganization" and "modes of innovative governance".

\subsection{Renew community space and improve the spatial structure of Historic Districts of Lhasa}

The spatial structure of the Historic Districts of Lhasa is mainly formed by temples, Lama's residence, dratsang, former aristocratic mansions and ordinary dwellings. The public space centers on Jokhang Temple, and it presents the level and form of the public space in the Historic Districts based on the use and status of buildings. The means of protection at all levels should be determined by means of space type screening and classification guidance. The multi-source data fusion method including GIS, big data, questionnaires is used to comprehensively judge the spatial renewal methods and construct the renewal strategies at different levels. Regarding the hierarchical public space centering on Jokhang Temple, it is more necessary to establish the system of historical and cultural protection and inheritance in the Historic Districts, restore its traditional pattern as well as protect the spatial scale and architectural style of the blocks in the Historic Districts so that the historical heritage with cultural value can be inherited and activated in the urban renewal.

Buddhism is naturally the main factor that influences the spatial pattern of the roads for reciting Buddhist scriptures in the Historic Districts of Lhasa. The spatial renewal needs to incorporate characteristic elements like nature, humanity and society in order to highlight local characteristics. To create good public space in the Historic Districts, the hierarchical dwelling space needs to configure facilities accurately and improve the complex utilization of the space. In this way, residents nearby and tourists will be attracted to the Historic Districts, and it effectively reduces the living cost of community residents and improves the happiness index of the inhabitants.

\subsection{Reorganize the community life and promote the diversified construction of the public space Historic Districts}

This paper explored the residents' behavioral patterns in the Historic Districts of Lhasa such as "walking and exploring", "daily communication activities", etc. It aimed to build an integrated unit, safe and healthy, with good facilities and orderly management in order that it can meet the needs of People's daily life.

The transit road plays a very important position in the road network of the historical district, and it is it that determines the road network structure of the entire historical district of Lhasa. Re-plan the original space and parking area in Lhasa's historic district to improve the safety of pedestrian travel, such as ensuring slow-traveling rights and dividing street use types; human-oriented transformation of road intersections to ensure pedestrian crossing safety, and single-lane organizations releasing slow-traveling Space; increase longitudinal passages to facilitate residents' travel; appropriately increase parking lots to solve the problem of parking difficulties in the old city. The water supply system in the historical district of Lhasa is imperfect, residents have difficulty in water use, sewage overflows and pollutes the environment, and the basic living conditions of the district are in urgent need of improvement; through gradual and small-scale environmental improvement, space guidance is strengthened to comprehensively improve the efficiency of public space utilization in the historical district. Implement a diversified collaborative participation mechanism, continue to improve the overall coordination, resident participation, project promotion, long-term management and other mechanisms, promote the joint participation of government, market supervision, and community departments to form a "diversified alliance" of interaction between the government, residents, and businesses . Relying on the development of tourism in Lhasa, a large-scale commercial agglomeration area has been formed in the historical district. However, due to the unreasonable development and utilization of cultural resources, the commercial forms are similar, the tourism products lack characteristics, the transmission of Tibetan traditional handicrafts is hindered, and the intangible cultural heritage Protection is facing dilemma. Therefore, the merchants are guided to adjust their business in an orderly manner to form a special consumption scene in Lhasa; through the transformation of the historical district environment and the integrated transformation of back streets, alleys and streets, a lively life scene with religious activities is formed; targeted creation according to the characteristics of the population structure Friendly and shared activity scenes, including local residents' living spaces, commercial communities, and vibrant communities that attract tourists to participate, etc., and diverse living scenes jointly shape the public space of historical districts.

5.3 Innovate the mode of community governance and construct the refined system about the public space renewal in the historical districts

To innovate the governance mode of public space in the historical districts of Lhasa, we should first change the

ISSN: 0010-8189

(C) CONVERTER 2021 
single use of public space. Instead, the public space should create a "holistic" space to meet the needs of users' activities in various aspects. The main activities of residents in the historical districts basically center on their daily living needs, and there are connections between local residents and non-local residents in terms of travel destination, travel frequency, travel type and travel mode. It is based on the service radius that can be radiated by different service facilities. In combination with the daily activity radius of community residents, residents' needs can be satisfied: they can reach the pharmacy, supermarkets, convenient stores, wholesale markets, bus stops and other facilities within 15 minutes. In order to meet the needs of community development and governance, "big data" and "cloud computing" in the context of modern Internet can make the community governance more refined, personalized and human-based, which will better meet the needs of local residents and tourists. Meanwhile, problems are transmitted to relevant departments so as to eliminate hidden dangers in time. The integration of the existing information resources can break the boundaries between departments to realize resource sharing, timely data warning and timely discovery of potential problems. The feedback and concerns of community residents are collected online, which will further influence the content and ways of social service in the community. On this basis, this paper constructed an efficient renewal system about the public space in the historical districts of Lhasa, which includes $15 \mathrm{~min}$ spatial circle activation, intelligent technology application and industrial linkage.

\section{Conclusion}

The formation of the urban public space is closely related to the unique phenological conditions, religious beliefs and folk customs of Tibet in the historical districts of Lhasa. Therefore, the research on the public space renewal in the historical districts of Lhasa was conducted from the perspective of community governance innovation, which marked an important transformation of urban renewal implementation from extensiveness to refinement. On the one hand, this paper started with the integration of community space and took the old inhabitants as the main objects. Next, this paper established the research structure through the service construction of residents' comprehensive needs. The public space structure of the historical districts is updated through the improvement of community space and the building of community living circles in order to promote the diversified construction of the historical districts. On the other hand, the community governance mode should be innovated, namely, a refined public space renewal system in the historical districts is constructed. It is characterized by the spatial living circles within 15 minutes, business function transformation and intelligent technology application. It is hoped that the research could not only solve the problem of public space renewal in the historical districts of Lhasa, but also provides reference for other historical districts which face the same difficulties in the public space renewal.

\section{Acknowledgements}

1.National Natural Science Foundation of China General Program: "The cultural ecological endogenous mechanism and its suitability renewal planning model in the historical section of Silk Road towns" (52078404)

2. Supported by Xian University of Architecture and Technology Science Foundation for Youths: "Research on the spatial orientation and optimization of subway transfer based on road-seeking behavior (QN1741)

\section{Reference}

[1] L.L. Rong, X.H. Feng, "Interpretation of traditional urban space in the old city of Lhasa," Low Carbon World, vol. 19, pp. 131-132, 2016.

[2] T. Kedrup, Q. Li, "On the protection and development of historical and cultural cities in China: the example of Lhasa old city,” Journal of Tibetan University (Social Science Edition), vol. 26, no. 02,pp. 53-62, 2011.

[3] X. Li, "Neighborhood Memory and Tourism Identity," Central University for Nationalities, 2013.

[4] F. Ding, George, W.J. Cao, "Reconstruction of aging-friendly public space and facility renewal under the integrated aging model of industrial communities," Packaging Engineering, vol. 39, no.16, pp. 167-177, 2018.

[5] J. Xiao, H.P. Li, K. Cao, "Study on the regional characteristics and layering process of Lhasa urban historical landscape," Journal of Architecture, vol. 09, pp.58-63, 2017.

[6] J. Xiao, K. Cao, "Feature identification and laminar interpretation of urban historical landscape in Weizang region,” China Garden, vol. 35, no. 10, pp.101-106, 2019.

ISSN: 0010-8189

(C) CONVERTER 2021 
[7] X.C. Deng, X.P. Fan, "Study on the spatial connection and inner vitality of Barkhor Street historical and cultural district," Planner, vol. 32, no.S2, pp.215-218+242, 2016.

[8] Minister of Housing and Urban-Rural Development Wang Menghui: Implementing urban renewal actions to promote high-quality urban development. Urban and rural construction, vol. 23, no.4, 2020.

[9] T. Zhong, B. Zhang, R. Chen, "Study on the ecological value transformation path of Chengdu's ecological zone around the city," Planner, vol. 36, no.19, pp.84-90, 2020.

[10] Y. Tang, "Urban renewal system construction - top-level design and grassroots creation," Urban Design, vol. 06, pp.30-37, 2019.

[11] L. Miao, "The current situation and development path of urban community governance in Tibet: Based on the perspective of innovative social governance," Journal of Aba Normal College, vol. 37, no.04, pp.95-100, 2020.

[12] W.Q. Xi, "Research on community planning and development of Shanghai central city from the perspective of social innovation governance," Planner Series, vol. 00, pp. 27-39, 2018.

[13] B.J. Zhao, W.Q. Xi, Q.Q. Wu, R. Wang, "Shaping resilient community communities: planning considerations and strategies for living circles," Shanghai Urban Planning, vol. 02, pp.14-19, 2020.

[14] T.L. Huang, Y.C. Mou, X.Y. Peng, "The cognition of the times, the core meaning and the implementation path of community planning in the new development stage," Planner, vol. 36, no. 20, pp.5-10, 2020 . 